\title{
Engineering a lipoxygenase from cyclocybe aegerita towards long chain polyunsaturated fatty acids
}

\author{
Dominik Karrer ${ }^{1}$, Martin Gand ${ }^{1}$ and Martin Rühl $1^{1,2^{*}}$ (D)
}

\begin{abstract}
The basidiomycetous lipoxygenase Lox 1 from Cyclocybe aegerita catalyzes the oxygenation of polyunsaturated fatty acids (PUFAs) with a high preference towards the C18-PUFA linoleic acid (C18:2 ( $\omega-6)$ ). In contrast, longer PUFAs, generally not present in the fungal cell such as eicosatrienoic acid (C20:3( $\omega-3))$ and docosatrienoic acid (C22:3 ( $\omega-3))$, are converted with drastically lower activities. With site-directed mutagenesis, we were able to create two variants with enhanced activities towards longer chain PUFAs. The W330L variant showed a $20 \%$ increased specific activity towards C20:3( $\omega-3)$, while a 2.5-fold increased activity against C22:3 ( $\omega-3)$ was accomplished by the V581 variant.
\end{abstract}

Keywords: Lipoxygenase, Mutagenesis, Biocatalysis, Protein engineering, Cyclocybe aegerita

\section{Introduction}

Lipoxygenases (LOX) are non-heme iron dependent dioxygenases that catalyze the insertion of molecular oxygen at a $(1 Z, 4 Z)$-pentadiene motif, which occurs e.g. in polyunsaturated fatty acids (PUFAs), in a regio- and stereospecific manner (An et al. 2018; Liavonchanka and Feussner 2006). In higher fungi of the phyla Basidiomycota, C18-PUFAs and especially linoleic acid are predominant, whereas C20-PUFAs like arachidonic acid and eicosapentaenoic acid were either found in very low amounts or in traces in fungi of the phyla Basidiomycota, such as in Cyclocybe aegerita (syn. Agroycbe aegerita), and Ascomycota like Phellinus sp. and Romaria sp. (Brodhun and Feussner 2011, Dembitsky et al. 1991, Landi et al. 2017). In general, studies on purified basidiomycetous LOX are scarce with only LOX from Pleurotus spp. and Cyclocybe aegerita described so far (Karrer and Rühl 2019; Kuribayashi et al. 2002; Leonhardt et al. 2013;

\footnotetext{
*Correspondence: martin.rueh|@uni-giessen.de

${ }^{2}$ Fraunhofer Institute for Molecular Biology and Applied Ecology IME Branch for Bioresources, Department of Biology and Chemistry, Justus-Liebig University Giessen, Institute of Food Chemistry and Food Biotechnology, Heinrich-Buff Ring 17, Giessen, Hesse 35392, Germany Full list of author information is available at the end of the article
}

Plagemann et al. 2013). For three of them it is known that they primarily produce 13 -hydroperoxy-9Z,11E-octadecadienoic acid (13-HPOD) and minor levels of 9-hydroperoxy-10E,12Z-octadecadienoic acid (9-HPOD) (Karrer and Rühl 2019; Kuribayashi et al. 2002; Plagemann et al. 2013). Furthermore, basidiomycetous LOX share a high preference towards C18-PUFAs of which linoleic acid was converted with the highest preference. With increasing chain length, the activity drastically decreases (Karrer and Rühl 2019). Yet, no study focused on the question which amino acids are the determining factors of the inefficient oxygenation of C20-C22-PUFAs. This shortcoming is addressed in this study by site-directed mutagenesis of three amino acid residues located in the substrate tunnel of the Lox 1 from Cyclocybe aegerita.

\section{Materials and methods}

Cloning and protein expression of CaeLOX1

The codon optimized LOX1 gene (accession number: MW013781), whose original cDNA was commercially purchased and cloned into the plasmid pET28a (BioCat GmbH, Heidelberg, Germany). For protein expression, pET28a/Lox1 plasmid was transformed into E. coli BL21-Gold (DE3) by adding 100 ng of plasmid-DNA

\section{Springer Open}

(c) The Author(s) 2021. This article is licensed under a Creative Commons Attribution 4.0 International License, which permits use, sharing, adaptation, distribution and reproduction in any medium or format, as long as you give appropriate credit to the original author(s) and the source, provide a link to the Creative Commons licence, and indicate if changes were made. The images or other third party material in this article are included in the article's Creative Commons licence, unless indicated otherwise in a credit line to the material. If material is not included in the article's Creative Commons licence and your intended use is not permitted by statutory regulation or exceeds the permitted use, you will need to obtain permission directly from the copyright holder. To view a copy of this licence, visit http://creativeco mmons.org/licenses/by/4.0/. 
to chemically competent cells. The mixture was incubated on ice for $30 \mathrm{~min}$, followed by a heat shock for 45 $\mathrm{s}$ at $42{ }^{\circ} \mathrm{C}$. After $5 \mathrm{~min}$ rest on ice, $500 \mu \mathrm{L}$ of LB-medium was added to the competent cells with a subsequent incubation period of $30 \mathrm{~min}$ at $37^{\circ} \mathrm{C}$. $200 \mu \mathrm{L}$ of the cell suspension was plated on LB-Agar, supplemented with kanamycin $\left(50 \mathrm{mg} \mathrm{L}^{-1}\right)$. After incubation over night at $37^{\circ} \mathrm{C}$, the obtained clones were used for protein expression. Recombinant E. coli cells were cultivated in autoinduction medium containing $10 \mathrm{~g}$ tryptone, $5 \mathrm{~g}$ yeast extract, supplemented with $50 \mathrm{mM} \mathrm{Na}{ }_{2} \mathrm{HPO}_{4}, 50 \mathrm{mM}$ $\mathrm{KH}_{2} \mathrm{PO}_{4}, 25 \mathrm{mM}\left(\mathrm{NH}_{4}\right)_{2} \mathrm{SO}_{4}, 0.5 \%$ (w/v) glycerol, $0.025 \%$ $(\mathrm{w} / \mathrm{v})$ glucose, $0.2 \%(\mathrm{w} / \mathrm{v})$ lactose and $50 \mathrm{mg} \mathrm{L}^{-1}$ kanamycin as selection marker, at $24{ }^{\circ} \mathrm{C}$ for $16 \mathrm{~h}$. Cells were harvested by centrifugation $\left(4.000 \mathrm{~g}, 30 \mathrm{~min}, 4^{\circ} \mathrm{C}\right)$ and stored at $-20{ }^{\circ} \mathrm{C}$ until further use.

\section{Protein purification}

The cell pellet was thawed on ice and resuspended in lysis-buffer (50 mM phosphate, $300 \mathrm{mM} \mathrm{NaCl}, \mathrm{pH} 7.5$ ). Disruption of cells was carried out by sonification (3 cycles for $60 \mathrm{~s}$ each with $60 \mathrm{~s}$ rest in between) on ice using a sonifier (Bandelin Sonopuls, Berlin, Germany). After complete disruption, cell debris was removed by centrifugation $\left(14.000 \mathrm{~g}, 30 \mathrm{~min}, 4^{\circ} \mathrm{C}\right)$. The resulting supernatant was further processed by using Ni-NTA spin columns (Qiagen, Hilden, Germany) following manufacturer instructions. The eluted protein (using $500 \mathrm{mM}$ imidazole in the elution buffer) was collected and subsequently concentrated and rebuffered in $50 \mathrm{mM}$ phosphate buffer ( $\mathrm{pH} 7.5$ ) by using Pall Nanosep ${ }^{\circledR}$ omega centrifugal devices (10 kDa cut off). The concentrated protein was analyzed via SDS-PAGE. Fractions with purified CaeLox1 were used for further analysis. Protein concentration was photometrically determined by using the $260 / 280$ ratio and the specific extinction coefficient $\left(\varepsilon_{280}\right.$ $\left.=102,135 \mathrm{M}^{-1} \mathrm{~cm}^{-1}\right)$, calculated with the ExPASy ProtParam tool (Gasteiger et al. 2005).

\section{Lipoxygenase assay}

LOX activity was determined by recording the formation of the conjugated double bond at $234 \mathrm{~nm}$ $\left(\varepsilon=25,000 \mathrm{M}^{-1} \mathrm{~cm}^{-1}\right)$ on a Nanophotometer (Implen, Munich, Germany). The reaction mixture contained 1.25 mM PUFA (Acros Organics: linoleic acid, linolenic acid, Cayman Chemicals: eicosatrienoic acid, docosatrienoic acid), $20 \mu \mathrm{L}$ enzyme solution and $50 \mathrm{mM}$ phosphate buffer, $\mathrm{pH} 7.5$ to a final volume of $1 \mathrm{~mL}$.

\section{Determination of $\mathrm{pH}$ - and temperature-optimum}

For the determination of the $\mathrm{pH}$-optimum, three different buffers were used: $50 \mathrm{mM}$ acetate buffer, $\mathrm{pH} 4.5-$ 6.0; $50 \mathrm{mM}$ phosphate buffer, $\mathrm{pH} 6.5-7.5$ and $50 \mathrm{mM}$ borate buffer, $\mathrm{pH}$ 8.0-10.0. Effects of the temperature were determined by incubating the reaction mixture at different temperatures, ranging from $4{ }^{\circ} \mathrm{C}-60{ }^{\circ} \mathrm{C}$.

\section{Site-directed mutagenesis}

For mutagenesis a modified QuikChange ${ }^{\circledR}$ protocol was used (Gand et al. 2016). The modified QuikChange ${ }^{\circledR}$ reaction mixture contained $1 \mu \mathrm{L}$ pET28a-Lox1-WT ( $50 \mathrm{ng} / \mu \mathrm{L}), 2.5 \mu \mathrm{L}$ forward primer, $2.5 \mu \mathrm{L}$ reverse primer (Table 1), $1 \mu \mathrm{L}$ dNTPs, $0.5 \mu \mathrm{L}$ Phusion-polymerase (Thermo Fisher Scientific), $10 \mu \mathrm{L} 5 \times$ GCbuffer, $1 \mu \mathrm{L}$ dimethylsulfoxide and $35 \mu \mathrm{L} \mathrm{ddH}_{2} \mathrm{O}$. PCR conditions with Phusion polymerase: initial denaturation for $3 \mathrm{~min}$ at $98{ }^{\circ} \mathrm{C}, 30 \mathrm{~s}$ denaturation at $98^{\circ} \mathrm{C}, 30$ s annealing at $62 / 64 / 66 / 68{ }^{\circ} \mathrm{C}$, elongation at $72{ }^{\circ} \mathrm{C}$ for 3:30 min, final elongation for $5 \mathrm{~min}$ at $72{ }^{\circ} \mathrm{C}$. Then, $2 \mu \mathrm{L}$ $D p n I$ (Thermo Fisher Scientific, Waltham, MA, USA) was added and the samples were incubated for $2 \mathrm{~h}$ at $37{ }^{\circ} \mathrm{C}$, followed by $D p n I$ inactivation at $80{ }^{\circ} \mathrm{C}$ for 10 min. Chemically competent E. coli Zymo $10 \beta$ (Zymo Research Europe GmbH, Freiburg, Germany) were transformed via heat shock with the PCR-products and plated out on LB-plates containing kanamycin as selection marker $\left(50 \mathrm{mg} \mathrm{L}^{-1}\right)$. After incubation over night at $37^{\circ} \mathrm{C}$, the obtained colonies were picked and used to inoculate fresh LB-medium with the according selection marker. After another incubation period over night at $37{ }^{\circ} \mathrm{C}$, the success of site-directed mutagenesis was confirmed via DNA-sequencing (Microsynth Seqlab, Göttingen, Germany).

\section{Homology modelling}

The crystal structure of the lipoxygenase from Glycine $\max$ (PDB: 1IK3) was used as template, sharing $43 \%$ sequence similarity. Models were calculated with SWISS-MODEL () (Guex et al. 2009) and visualized with Chimera 1.13.1 (Pettersen et al. 2004).

\section{Table 1 Primer sequences for site-directed mutagenesis}

\begin{tabular}{|c|c|}
\hline primer & sequence \\
\hline fw_Lox1-1393F & 5'-ccgagtatggttgccccgtttagttattttaaaattccgg-3' \\
\hline rv_Lox1-I393F & 5'-ccggaattttaaaataactaaacggggcaaccatactcgg-3' \\
\hline fW_Lox1-V581A & $5^{\prime}$-gatgatggcacaggcgccgtatctgctgag-3' \\
\hline rv_Lox1-V581A & 5'-ctcagcagatacggcgcctgtgccatcatc-3' \\
\hline fW_Lox1-V581F & $5^{\prime}$-gatgatggcacagtttccgtatctgctgag-3" \\
\hline rv_Lox1-V581F & 5'-ctcagcagatacggaaactgtgccatcatc-3' \\
\hline fW_Lox1-W330L & 5'-caggtgagcgatctgacccgtcatgaactg-3' \\
\hline rv_Lox1-W330L & 5'-cagttcatgacgggtcagatcgctcacctg-3' \\
\hline
\end{tabular}




\section{Molecular docking}

Autodock Vina was used for docking analysis. For each docking run, a box was defined which covered the active site with a grid of $22 \times 18 \times 26 \AA$. All parameters were set on standard (Trott et al. 2010).

\section{Results}

\section{Bioinformatic analysis and homology modelling}

Shape and specificity of mammalian LOX or the regioselectivity of LOX from plants were investigated by various studies. It was pointed out that specific bulky/aliphatic amino acid residues in the substrate tunnel can affect substrate orientation and, therefore, be crucial for substrate specificity (Borngräber et al. 1999; Brodhun et al. 2013; Hornung et al. 2008). A comparison of sequence alignments of already characterized basidiomycetous LOX, assisted by the homology model of CaeLox1, shows that in their substrate tunnel the amino acid W330 is highly conserved and the amino acid hydrophobicity at the positions I393 and V581 are very similar (Fig. 1a, b). Furthermore, molecular docking in a carboxyl-end towards the stabilizing $\mathrm{K} 540$ orientation was calcu-

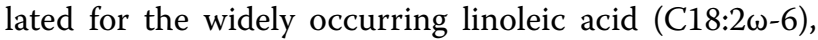
linolenic acid $(\mathrm{C} 18: 3 \omega-3)$ as well as for the rare PUFAs eicosatrienoic acid (C20:3 $\omega-3)$ and docosatrienoic acid $(\mathrm{C} 22: 3 \omega-3)$. This revealed that the residues W330, I393 and V581 are indeed in interacting distance, with less than $5 \AA$, to the carboxy-end and middle section of the tested PUFAs (Fig. 2a-d).

\section{Temperature and $\mathrm{pH}$ optimum}

In acidic environment ( $\mathrm{pH} 4.5-6.0)$, the CaeLox1 activity remained very low with about $10 \%$ of the maximum activity. A drastic increase in activity was detected with increasing $\mathrm{pH}$ reaching its maximum at 7.5. Further increase of the $\mathrm{pH}$ resulted in a drastic loss with no detectable activity from $\mathrm{pH} 9.5$ and above (Fig. 3a). The effect of the temperature on the activity of CaeLox1 was determined in a temperature range between $4{ }^{\circ} \mathrm{C}$ and 60 ${ }^{\circ} \mathrm{C}$. The highest activity was detected at $25^{\circ} \mathrm{C}$. A steady loss of activity to about $80 \%$ was detected when increasing the temperature from 25 to $45{ }^{\circ} \mathrm{C}$. With a further temperature increase to $50{ }^{\circ} \mathrm{C}$ and $60^{\circ} \mathrm{C}$ no activity could be detected. At $4{ }^{\circ} \mathrm{C} 10 \%$ of the maximal LOX activity remained (Fig. 3b). Based on these results, any further experiments were conducted at $\mathrm{pH} 7.5$ and $25^{\circ} \mathrm{C}$.

\section{Specific activities towards various PUFAs}

To experimentally verify the role of W330, I393 and V581 in PUFA oxygenation, we investigated the specific activities of PUFAs occurring (linoleic acid, linolenic acid) and non-occurring (eicosatrienoic- and docosatrienoic acid) in fungi of the phylum Basidiomycota. Expanding the size of the substrate tunnel (V581A), putatively stabilizing the middle-section of the substrate in a carboxylate-end first orientation (Fig. 1), led to a 3-fold loss of activity, while a reduced size $(\mathrm{V} 581 \mathrm{~F})$ resulted in a $\sim 2.5$-fold decrease of activity towards linoleic acid (Fig. 4a). With the same mutations, similar differences in activities towards linolenic acid were observed in comparison to the wild type. Interestingly, the observed effects of the V581A/F mutations changed with increasing chain length of the fatty acid. Compared to C18-PUFAs, the V581F variant showed only a $<2$-fold difference in activity towards C2022:3( $\omega-3)$-PUFAs eicosatrienoic acid and docosatrienoic acid (Fig. 4c, d). Furthermore, a 2.5-fold increased activity against docosatrienoic acid was detected for the V581A variant, representing $50 \%$ of the WT activity towards the natural substrate linoleic acid. Tightening the substrate tunnel receiving the carboxy-end of the PUFAs with the I393F variant, a 3-fold decrease was observed against C18-PUFAs while $\mathrm{C} 20$ - and C22-PUFAs were less affected by this mutation. CaeLox1 mutation W330L, which leads to a widening of the substrate tunnel, resulted in only $\sim 15 \%$ of the activity towards linoleic acid in comparison to the wild type LOX CaeLox1. Surprisingly in this mutant (W330L), the conversion of eicosatrienoic acid was increased by $\sim 20 \%$ compared to linoleic acid. However, the W330L variant showed a $\sim 60 \%$ reduction in the activity to docosatrienoic acid (Fig. 4c, d). Due to the increased specific activity of the W330L and V581A variants towards the C20-22:3( $\omega-3)$-PUFAs, the double mutant W330L/V581A was created. This variant exhibited similar or even lower specific activities towards C18- as well as C20-22-PUFAs, compared to the single mutations V581A and W330L (Fig. 4a-d).

\section{Discussion}

Both variants V581A and V581F showed similar activities to the fungal occurring PUFAs (linoleic acid and linolenic acid) compared to the wild type LOX, which suggests that neither increasing or decreasing space at that position leads to significantly higher activities but rather interfere with an efficient substrate binding of C18-PUFAs (Fig. 4a, b). The observed effects of the V581A/F mutations changed with increasing chain length, suggesting that alteration of space inside the tunnel seems to get relevant for longer chain PUFAs (Fig. 4c, d). Due to an additional $\mathrm{C}=\mathrm{C}$ double bond in long chain PUFAs like $\mathrm{C} 20(\omega-3)$, which leads to lessened flexibility of the alkyl-chain, providing extra space seems to be beneficial. On the other hand, linoleic acid that harbors two $\mathrm{C}=\mathrm{C}$ bonds resulting in increased flexibility of the alkyl-chain, seems to require a tighter substrate tunnel for an optimal substrate orientation. 
a

WRYAKTCAQ - SDWWARE - - HL - THLLVEA - IVAAQR - LP - SHIVF - LLSPHW - - TLSLNALAR - VLVP

PosLoX WRYAKTCVLSSDWALHEMIIHLNNTHLVEEAVIVAAQRKLSPSHIVFRLLEPHWVVTLSLNALARSVLIP 374

PsaLOX WRYAKTCVLSSDWALHEMIIHLNNTHLVEEAVIVAAQRKLSPSHIVFRLLEPHWVVTLSLNALARSVLIP 374

CaeLox1 WRYAKMCAQASDWVRHEVGVHLTLTHLVEEAI IVAAQRSLPDSHIVHTLLSPHWLRTLSLNSMARMILVP 439

Caelox4 WRYAKMCAQVSDWTRHELAVHLVHTHFVEATIVAAQRSFPDSHVFALLSHWITTLSLNALAREVLVP 387

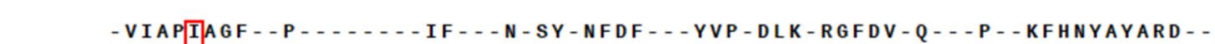

PosLox EVIVPIAGFSAP-.-.-HIFQFIRESFTNFDWKSLYVPADLESRGFPVDQLNS - - KFHNYAYARDIN 435

PsaLox EVIVPIAGFSAP--..- - HIFQFIRGSFTNFDWKSLYVPADLESRGFPIDQLNSP- - KFHNYAYARDIN 435

CaeLox1 DMIAALAPFKLT - . - . - EIKALCNYTYHSFDFAGHYIPEDLKNRGFDVAHFDNPFGQFHNAYARDMA 502

CaeLoX4 SMVAPISYFKIP...... EIFAICNDAYHSFDFVGYYPNDMKRRGFDVSQFDDPKGKFHNYAYRDVA 450

AAPQHTAVINYLQQYY - TFVPNKPSALF - PLP - SL - L L - YTE - DL - - ALPL - - - - - - - WLLMAQ - PYL

PosLox AAPQHTAVNYLQQYYTFVPNKPSALFSLPTSIAQLQKYTESDLMAALPLNAK- - -RQWLLMAQIPYL 571

PsaLox AAPQHTAVNYLQQYYQTFVPNPSALFSPLPKSIAQLQKYTESDLMAALPLNAK- - -RQWLLMAQIPYL 571

CaeLox1 AAPQHTSINYLQQYYLTYVPSRPSALFAPPPTSLRELTAYKEADVLKALPLQSR-- - NTWLLMAQYPYL 636

CaeLox4 AAPQHTAVNYLQQFYLSFVPNKPSALFAPLPQTLQELQGFKEQDILKALPLQSQ - - - - VSWLMMAQVPYL 584

LS - - VE - - - IIVTYA-NAS - - . - . - . - P - IA - AG - - L - DLK - L - - F - ISAQ - DDQ - T - Y

PosLox LSMQVQEDENIVTYAANASTDK -.......... DPIIASAGRQLAADLKKLAAVFLVNSAQLDDQNTPY 629

PsaLox LSMQVQEDENIVTYAANASTDK - . . . . . . . DPIIASAGRQLAADLKKLAAVFLANSSOLDDONTPY 629

CaeLox1 LSAEVEPENNIVSYAKNASKSW-.........

CaeLox4 LSAEVEPENNITYYGEAANSR - . . . . . . . . . NPLIAQAGKVLQKDVATLGMTFKDISDQMDDQGTKY 642
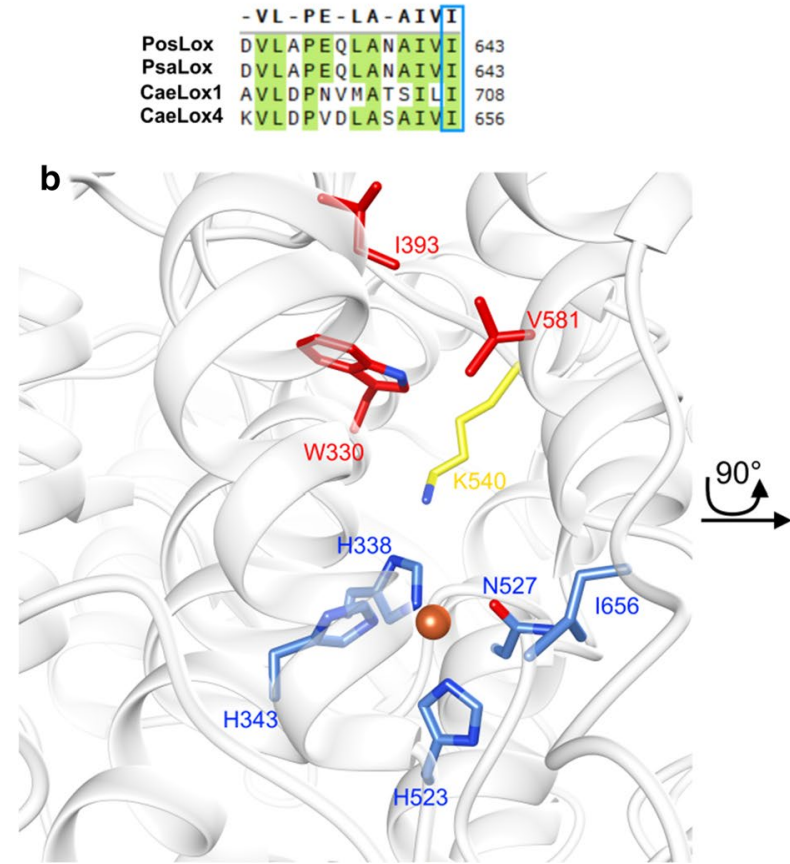

Fig. 1 a Partial sequence alignment of various LOX. Cyclocybe aegerita CaeLox1 (MW013781), CaeLox4 (MK451709), Pleurotus sapidus PsaLOX (CCV01580), Pleurotus ostreatus PosLOX (CCV01578). Alignment was carried out by using Clustal Omega with default parameters. The highlighted amino acid residues involved in iron binding are highlighted in blue. Amino acids considered to be involved in selectivity and activity by shaping the substrate tunnel are highlighted in red. Amino acid residues considered to interact with the carboxylate end of the substrate via ionic interactions are highlighted in yellow. $\mathbf{b}$ Substrate tunnel of the homology model of CaeLox1. Iron (orange) binding amino acid residues are highlighted as blue sticks ( $\mathrm{H338}, \mathrm{H343}, \mathrm{H} 523, \mathrm{~N} 527,1656)$ and the positively charged amino acid at the bottom of the substrate tunnel is highlighted in yellow sticks. Amino acid residues involved in shaping the substrate tunnel are shown as red sticks (V581, 1393 and W330). Oxygen inside the amino acid side chains are colored in red and nitrogen in blue

Although the increased chain length in comparison to the eicosatrienoic acid leads to a higher flexibility, the conformation of docosatrienoic acid in the substrate tunnel without a tryptophan might be unsuitable (Fig. 4c, d). Previous studies investigated the role of the amino acid residues W500 and W523, located in the substrate tunnel of LOX-1 from soybeans and a LOX from pea seeds (Hughes et al. 2001; Ruddat et al. 2004). Increasing space at position W500 of LOX-1 from soybeans revealed a decrease of activity towards linoleic acid and arachidonic acid (Ruddat et al. 2004). Furthermore, the W523A variant of a LOX from pea seeds 


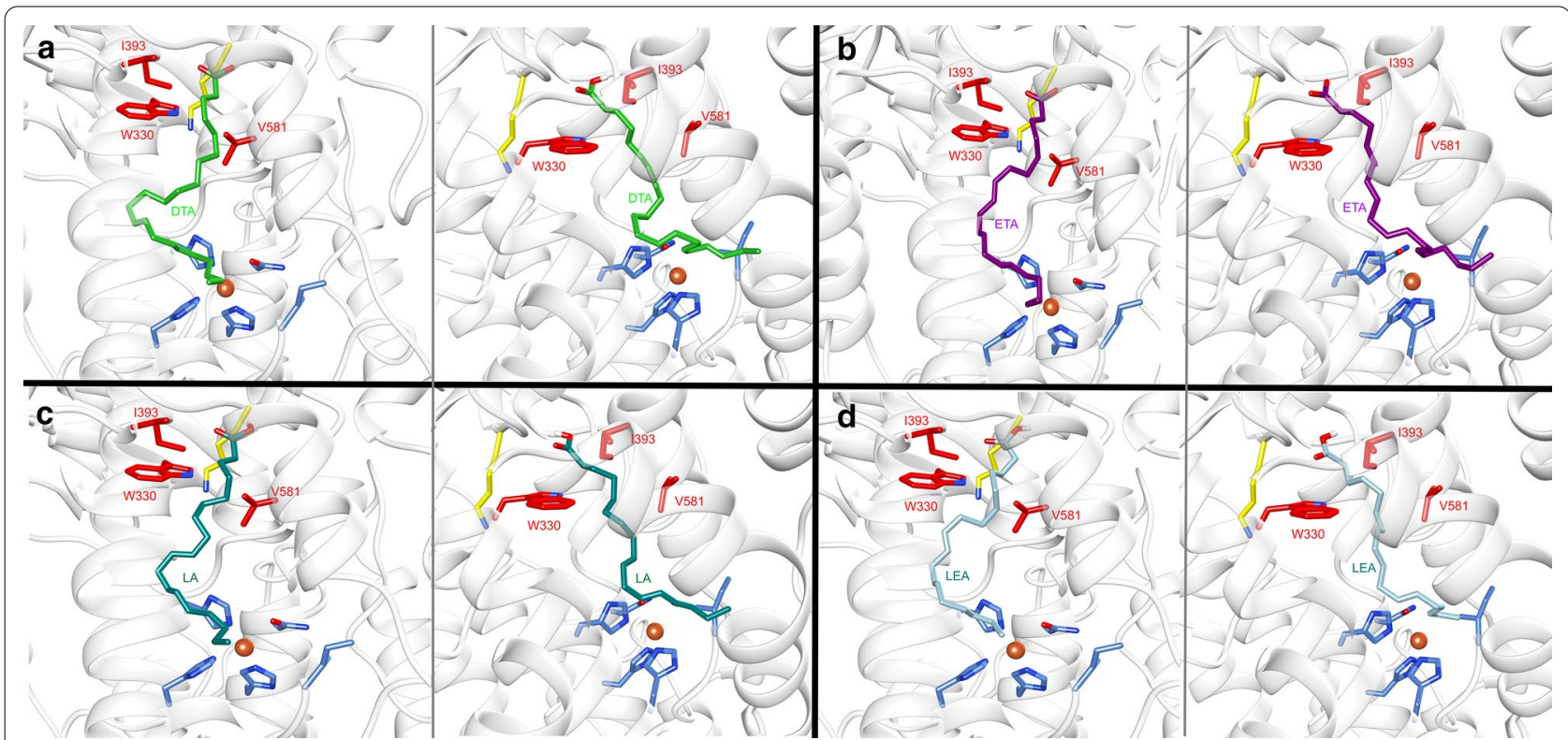

Fig. 2 Molecular docking of a docosatrienoic acid (DTA, green sticks), b eicosatrienoic acid (ETA, magenta sticks), c linoleic acid (LA, cyan sticks) and d linolenic acid (LEA, light blue sticks) into the homology model of CaeLox1. Iron (orange) binding amino acid residues are highlighted as blue sticks $(\mathrm{H} 338, \mathrm{H} 343, \mathrm{H} 523, \mathrm{~N} 527, \mathrm{l656})$ and the positively charged amino acid at the bottom of the substrate tunnel is highlighted in yellow sticks. Amino acid residues involved in shaping the substrate tunnel are shown as red sticks (V581, I393 and W330). Oxygen inside the amino acid side chains are colored in red and nitrogen in blue
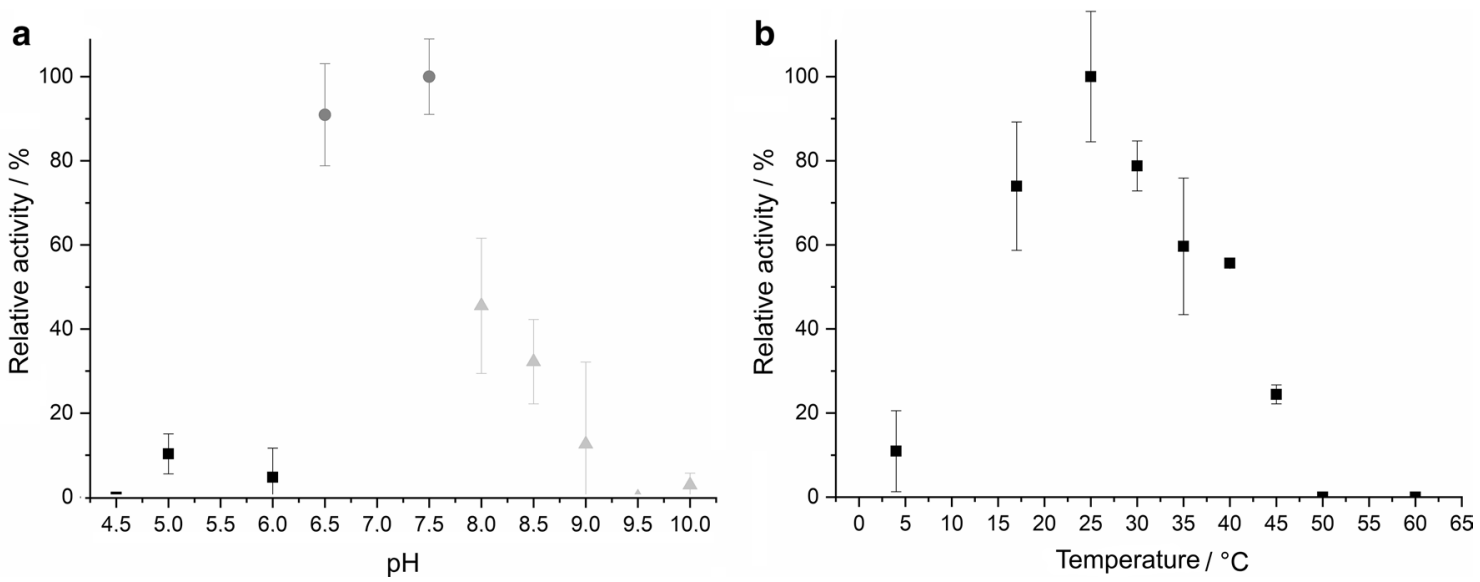

Fig. 3 Effects of $\mathrm{pH}$ (a) and temperature (b) on CaeLox1 activity. buffers used: $50 \mathrm{mM}$ acetate (squares) from pH 4.5-6.0, $50 \mathrm{mM}$ phosphate (circles) from $\mathrm{pH}$ 6.5-7.5, $50 \mathrm{mM}$ borate (triangles) from $\mathrm{pH} 8.0-10.0$

showed no difference in activity towards linolenic acid but a $\sim 6$-fold decrease towards the longer arachidonic acid (Hughes et al. 2001). This is partly in accordance with our results, since we were able to show spacing at this position (corresponds to W330 in CaeLox1) plays a beneficial role for the C-20( $\omega$-3)-PUFA eicosatrienoic acid. By combining the mutations V581A and W330L to the V581A/W330L variant, the beneficial effects of the single mutations for C-20-22( $\omega-3)$-PUFAs seem to neutralize each other (Fig. 4c, d). This demonstrates the challenges in efficient protein engineering of lipoxygenases. Due to the long carbon chain of fatty acids, a large number of substrate conformations, their interactions with the residues of the tunnel as well as physicochemical effects have to be taken into account which makes a general prediction of important amino acid 

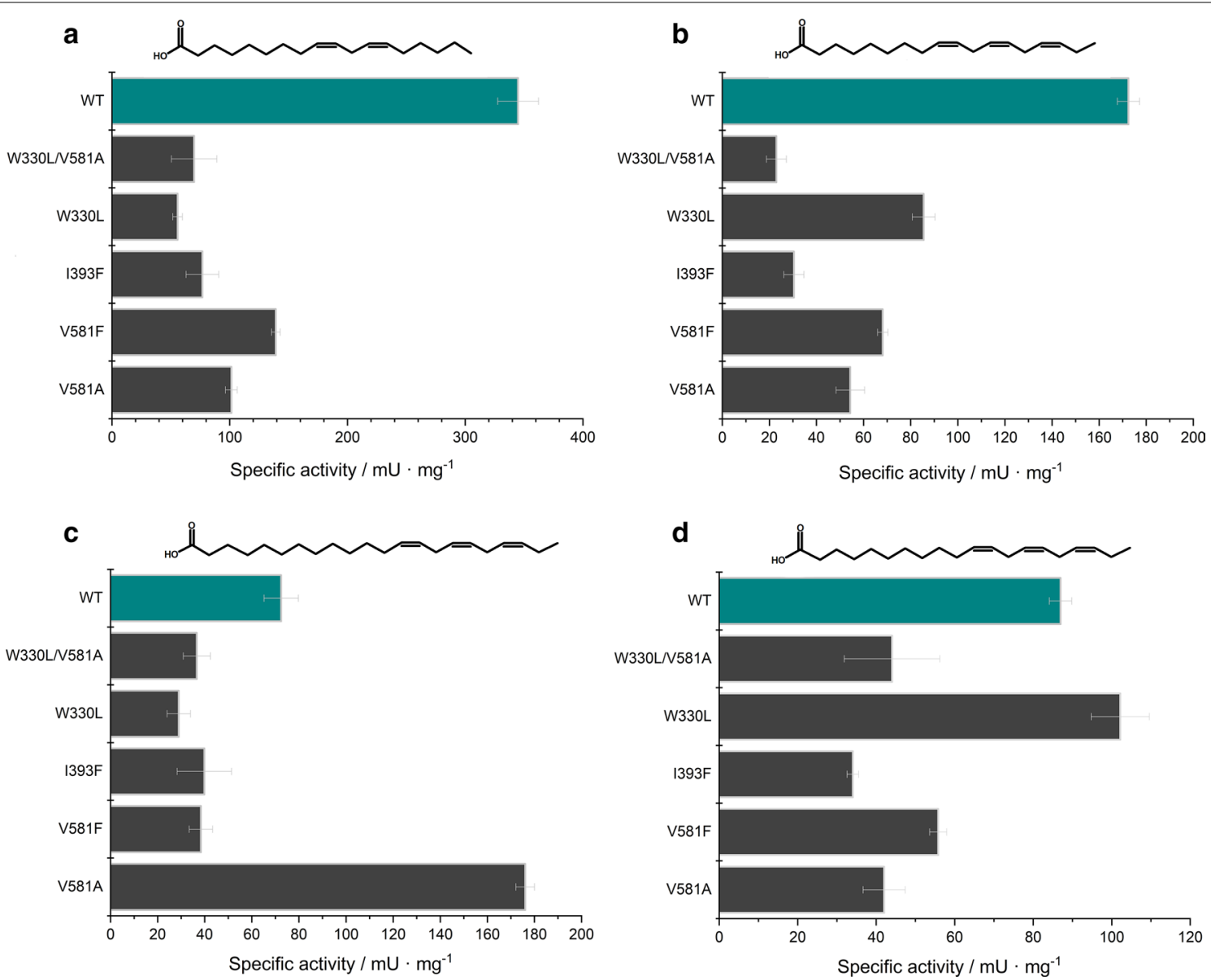

Fig. 4 Specific activities of CaeLox1-variants compared to the wild type against a linoleic acid, $\mathbf{b}$ linolenic acid, $\mathbf{c}$ docosatrienoic acid and $\mathbf{d}$ eicosatrienoic acid

residues in the substrate tunnel difficult. Besides the mentioned studies, no other mutagenesis studies with long chain PUFAs are existent.

\section{Acknowledgements}

We thank Niklas Broel and Alexander Atamasov for their support in the experiments.

\section{Authors' contributions}

DK, MG and MR conceived and designed research. DK and MG conducted experiments. DK analyzed data. DK, MG and MR wrote the manuscript. All authors read and approved the manuscript.

\section{Funding}

Open Access funding enabled and organized by Projekt DEAL. Not applicable.

\section{Availability of data and materials}

All relevant data for this article are included within this manuscript. The GenBank accession number for the LOX1 gene is MW013781.

\section{Consent of publication}

Not applicable.

\section{Competing interests}

No relevant financial or non-financial competing interests are to report.

\section{Author details}

${ }^{1}$ Institute of Food Chemistry and Food Biotechnology, Justus-Liebig University Giessen, Institute of Food Chemistry and Food Biotechnology, Heinrich-Buff Ring 17, Giessen, Hesse 35392, Germany. ${ }^{2}$ Fraunhofer Institute for Molecular Biology and Applied Ecology IME Branch for Bioresources, Department of Biology and Chemistry, Justus-Liebig University Giessen, Institute of Food Chemistry and Food Biotechnology, Heinrich-Buff Ring 17, Giessen, Hesse 35392, Germany.

Received: 26 October 2020 Accepted: 16 February 2021

Published online: 04 March 2021

\section{References}

An JU, Hong SH, Oh DK (2018) Regiospecificity of a novel bacterial lipoxygenase from Myxococcus xanthus for polyunsaturated fatty acids. Biochim Biophys Acta Mol Cell Biol Lipids 8:823-833

Borngräber S, Browner M, Gillmor S, Gerth C, Anton M, Fletterick R, Kühn H (1999) Shape and specificity in mammalian 15-Lipoxygenase active site. J Biol Chem 52:37345-37350

Brodhun F, Feussner I (2011) Oxylipins in fungi. FEBS J 278:1047-1063

Brodhun F, Cristobal-Sarramian A, Zabel S, Newie J, Hamberg M, Feussner I (2013) An 13S-Lipoxygenase with an a-linolenic acid specific hydroperoxidase activity from Fusarium oxysporum. PLoS ONE e64919 
Gand M, Thöle C, Müller H, Brundiek H, Bashiri G, Höhne M (2016) A NADHaccepting imine reductase variant: Immobilization and cofactor regeneration by oxidative deamination. J Biotechnol 230:11-18

Gasteiger E, Hoogland C, Gattiker A, Duvaud S, Wilkins M, Appel RD, Bairoch A (2005) Protein Identification and Analysis Tools on the ExPASy Server. In: Ed.: John M, Walker The Proteomics Protocols Handbook. Humana Press, Totowa New Jersey

Guex N, Peitsch MC, Schwede T (2009) Automated comparative protein structure modeling with SWISS-MODEL and swiss-PdbViewer: A historical perspective. Electrophoresis 30:162-173

Hornung E, Kunze S, Liavonchanka A, Zimmermann G, Kühn D, Fritsche K (2008) Identification of an amino acid determinant of $\mathrm{pH}$ regiospecificity in a seed lipoxygenase from Momordica charantia. Phytochemistry 69:2774-2780

Hughes RK, Lawson DM, Hornostay AR, Fairhurst SA, Casey R (2001) Mutagenesis and modelling of linoleate binding pea seed lipoxygenase. Eur J Biochem 268:1030-1040

Karrer D, Rühl M (2019) A new lipoxygenase from the agaric fungus Agrocybe aegerita: Biochemical characterization and kinetic properties. PLOS ONE 15:e0218625

Kuribayashi T, Kaise H, Uno C, Hara T, Hayakawa T, Joh T (2002) Purification and characterization of lipoxygenase from Pleurotus ostreatus. J Agric Food Chem 50:1247-1253
Leonhardt R-B, Plagemann I, Linke D, Zelena K, Berger RG (2013) Orthologous lipoxygenases of Pleurotus spp. - A comparison of substrate specificity and sequence homology. J Mol Catal B: Enzym 97:189-195

Liavonchanka A, Feussner I (2006) Lipoxygenases: occurrence, functions and catalysis. J Plant Physiol 163:348-357

Plagemann I, Zelena K, Arendt P, Ringel PD, Krings U, Berger R (2013) LOXPsa1, the first recombinant lipoxygenase from a basidiomycete fungus. J Mol Catal B: Enzym 87:99-104

Pettersen EF, Goddard TD, Huang CC, Couch GS, Greenblatt DM, Meng EC, Ferrin TE (2004) UCSF Chimera - a visualization system for exploratory research and analysis. J Comput Chem 25:1605-1612

Ruddat VC, Mogul R, Chorny I, Chen C, Perrin N, Whitman S, Kenyon V, Jacobson MP, Bernasconi CF, Holman TR (2004) Tryptophane 500 and arginine 707 define product and substrate active site binding in soybean lipoxygenase-1. Biochemistry 41:13063-13071

Trott O, Olson AJ (2010) AutoDock Vina: improving the speed and accuracy of docking with a new scoring function, efficient optimization and multithreading. J Comput Chem 2010 31:455-461

\section{Publisher's note}

Springer Nature remains neutral with regard to jurisdictional claims in published maps and institutional affiliations.

\section{Submit your manuscript to a SpringerOpen ${ }^{\circ}$ journal and benefit from:}

- Convenient online submission

$\checkmark$ Rigorous peer review

- Open access: articles freely available online

- High visibility within the field

- Retaining the copyright to your article

Submit your next manuscript at $\boldsymbol{\nabla}$ springeropen.com 